Enhancing life skills development: Chinese adolescents' perceptions

Mantak Yuen

The University of Hong Kong, China

Raymond M. C. Chan

Hong Kong Baptist University, China

Norman C. Gysbers

University of Missouri-Columbia, USA

Patrick S. Y. Lau Queenie Lee

The Chinese University of Hong Kong, China

Peter M.K. Shea

Hong Kong Council of the Church of Christ in China, China

Ricci W. Fong Y B Chung

The University of Hong Kong, China

Revised for Pastoral Care in Education

First submission April 2010; revised June 4 2010; revised June 30 2010;

accepted June 302010 


\section{About the authors}

Mantak Yuen is an associate professor and Ricci W. Fong and Y.B. Chung are graduate students in the Faculty of Education, at the University of Hong Kong. Patrick S. Y. Lau is a professor and Queenie Lee a graduate student in the Department of Educational Psychology, the Chinese University of Hong Kong. Norman C. Gysbers is Curators' Professor in the Department of School, Educational, and Counseling Psychology, University of Missouri-Columbia. Raymond M. C. Chan is an associate professor in the Department of Education Studies, Hong Kong Baptist University. Peter M. K. Shea is an educational psychologist in the educational psychological services, Hong Kong Council of Church of Christ in China.

Correspondence regarding this article should be sent to: Mantak Yuen, Faculty of Education, University of Hong Kong. Pokfulam Road, Hong Kong, China (e-mail: mtyuen@hku.hk). 


\title{
Enhancing life skills development: Chinese adolescents' perceptions
}

\begin{abstract}
This study explored Chinese adolescents' perceptions of their own life skills development and the importance they place on such skills. The study also investigated the within-school and outside-school influences that may help develop and enhance life skills development. Six focus groups involving 52 high school students were conducted, using a set of predetermined discussion topics. Results revealed students' awareness of many salient life skills, including those related directly to academic development, 'learning to learn', personal and social growth, and future career planning. The students were also able to suggest practical strategies that schools might use to further enhance students' life skills development. Contextual factors influencing the development of life skills appear to include not only experiences within the school curriculum and the guidance and counselling programme, but also talent development opportunities, and family and peer relationships. The implications of the findings are discussed with particular reference to implementing comprehensive school guidance and counselling programmes in Hong Kong.
\end{abstract}

Keywords: Life skills; comprehensive school guidance and counselling programmes; Chinese; adolescents 


\section{Promoting life skills development: Chinese adolescents' perceptions}

\section{Introduction}

Education for life has become the ultimate goal for schooling in this fast-changing, highlycompetitive world (Gysbers, 2003; Education Commission, HK, 2002). Schools strive to equip their students with a set of generic transferable skills which enable them to take on various functions and life roles such as learners, friends, workers, parents and citizens. A student's 'life skills' comprise a set of everyday competencies and perceived self-efficacy that facilitate academic progress, personal and social development, and career planning. Examples include (inter alia) study skills, interpersonal relationship skills, self-management and leadership skills, skills in problem solving, career decision-making, and strategies to further develop and utilize one's talents (Yuen, Lau, Leung, Shea, Chan, Hui, \& Gysbers, 2003). A more comprehensive list of life skills in various domains can be found online in the Unicef (2009) website at: http://www.unicef.org/lifeskills/index_whichskills.html

It is important to note here that although the term 'skills' is most commonly used in relation to these everyday competencies, some of the 'skills' could be more accurately described as essential 'attitudes of mind' or 'predispositions'. Examples include persistence, resilience, effort, work ethic, optimism, empathy, respect, responsibility, integrity, and initiative.

The concept of life skills development covers a wide spectrum, and few researchers have so far studied all aspects as an integrated paradigm. Research literature has mostly focused on 
the individual components which could be incorporated in a holistic concept of life skills for instance, decision making (Michels, Kropp, Eyre, \& Halpern-Felsher, 2005), conflict management (Becker \& Luthar, 2007; Botvin, Griffin, \& Nichols, 2006) and career exploration (Phipps, 1995). Investigations into the topic are lacking within the Chinese community, and particularly so in relation to adolescents who are at a critical developmental stage for acquiring key life skills.

It is reasonable to wonder if life skills are simply acquired incidentally and spontaneously through everyday experiences, or if they can be fostered or taught directly or indirectly. Many skills are undoubtedly acquired incidentally without direct teaching. For example, within the family context, a student's relationships with parents, and often grandparents, and siblings play an important role in life skills development by promoting personal and social development in areas such as communication, understanding of others, empathy, responsibility, cooperation, negotiation, and leadership. The same is true of interactions with one's peers, both inside and out of school. However there are many possible strategies available for enhancing skill development within the school context. There are obvious opportunities to help students develop and strengthen skills such as techniques for study, cooperating with others, critical thinking, problem solving, leadership, conflict resolution and negotiation within the general curriculum and as part of all extra-curricular activities. A school's guidance and counseling program can also contribute significantly to life skills development in a number of ways. For 
example, implementation of high quality guidance and counseling programs can enable school personnel to offer effective support for students' 'whole person' development, including their acquisition of vital life skills and their planning for life beyond school (Lang, 2003; Sun \& Hui, 2007; Yuen et al., 2002).

One of the key influences on how effectively adolescents make the transition from childhood to adult life, and acquire the necessary life skills on the way, is how successfully they cope with the many physical and emotional changes that occur for them during puberty (Santrock, 2008; Wieten, 2001). Researchers have shown that physical and hormonal changes, together with familial, school, and environmental factors, influence students' perceptions about themselves, their motivations, their relationship with peers, how they react to peer group pressures, and their attitude toward authority (Gottlieb, Wahslsten, \& Lickliter, 2006; Gould, Greenberg, Velting, \& Shaffer, 2003; Ormrod, 2008). Any interventions designed to enhance students' life skills development must take into account the students' stage of physical development and their emotional and social maturity.

In order to promote the implementation of life skills development curriculum in schools in Hong Kong, Yuen et al. (2003) launched the Life Skills Development Project, drawing on Bandura's self-efficacy theory (1990) and the conceptual framework of comprehensive counseling programs that address life skills competency domains identified in previous research (e.g., Gysber \& Henderson, 2000; Gysbers, Lapan, Multon, \& Lukin, 1996). The Life Skills 
Development Project is committed to promote life skills development among students through a whole-school approach to comprehensive developmental guidance in schools (Yuen, 2008).

Within the context of current curriculum reforms in Hong Kong, schools have to provide career-related experiences to all high school students. The 'individual student planning' component of the comprehensive counseling programs has influenced the Hong Kong Association of Careers Masters and Guidance Masters to initiate a project to develop curriculum resources for career education for high school students (Ho, 2008; McMahon \& Yuen, 2009).

Implementation of the Life Skills Development Project ultimately led the researchers to investigate students' own perceptions of what constitutes life skills and how acquisition of these skills might relate to the support they have received from their schools. The results of that study are reported here. This is the first study exploring associations between the comprehensive counseling programme and Chinese adolescents' life skills development in Hong Kong.

\section{Research questions}

The purpose of the focus group study was to explore the following issues:

1. What are adolescent students' perceptions of the skills, attitudes and behaviours they believe necessary for operating effectively now and in the future in school, home and community?

2. From the adolescents' perspective, what are the chief influences that determine how effectively they acquire life skills; and what more might schools do in this area? 


\section{Method}

The study involved 52 Hong Kong high school adolescents in six focus groups (boys = 23, girls = 29; Grade 10 students =18, Grade 12 students=34). These students came from schools in different parts of the territory, with student intakes covering a wide range of ability. All participants were nominated by their guidance teachers (i.e. teachers with a role as mentors and counsellors for the students they teach). The students selected were all leaders or students who were active in extra-curricular activities and had volunteered to share their high school experiences.

The researcher and an experienced school teacher with guidance duties acted as moderators for the focus groups, following procedures outlined by Morgan (1988). The focus groups were conducted in Cantonese, the mother tongue of most Chinese students in Hong Kong. The participants were asked to describe examples of life skills from their own experience as high school students, and how the school guidance and counseling program in any way enhanced their life skills development. (See Appendix 1 for the English version of the semistructured interview guide for the focus groups).

The researchers were aware of the possible weaknesses in data collected through the focus groups, including the following potential limitations: (i) by introducing leading questions or issues through the moderator, the students may be led to focus too much on matters that would not necessarily arise if the discussion was completely open; (ii) participants may make 
remarks that they hope will 'please' or 'satisfy' the interviewer, rather than giving totally honest observations; (iii) the participants in the small group may not represent the views of the majority of other students, particularly when they have been specially selected, as in this study; (iv) discussions can be monopolized by the most assertive group members; (v) sometimes the fine detail of comments can be lost when transcribed; and even more so when later translated into another language; (vi) time constraints sometimes mean that discussions are cut short and some issues are not raised; (vii) the approach requires good facilitation skills of the moderators (Carey, 1995; Halcomb, Gholizadeth, Digiacomo, Phillips, \& Davidson, 2007; Wright, Wilson, Griffin, \& Evans, 2010). In the present study, the moderators were experienced in facilitating group discussions and they made every effort to hear the adolescents' opinions using the focus group process (Puchta \& Potter, 2004).

A research assistant helped to record the sessions on tape, made notes, and later transcribed the tapes (in Chinese). The data were analyzed following the procedures of data reduction, data display, interpretation and drawing conclusions (Miles \& Huberman, 1994). Preliminary coding labels were used to code transcripts. The researcher and co-moderator read the transcripts several times and discussed the categories of response that seemed to emerge naturally from the data. Each meaningful unit in the transcript was underlined, classified, and labeled with an appropriate category. In addition, an experienced school guidance teacher was 
invited to act as an independent reviewer to check the categories the researchers had developed.

Comparing the independent reviewer's and the researchers' categories and sub-categories for all the protocols, the inter-rater agreement (reliability) was found to be very high at .92 . Some very minor adjustments in labeling and grouping of categories and sub-categories were then made.

\section{Results}

In response to the first discussion topic, namely, adolescent students' perceptions of skills, attitudes and behaviours necessary for operating effectively in school, home and community, there was clear evidence that all students in the group understood the concept of life skills. They were able to give examples of situations where they had to employ such skills and could identify experiences that help them develop such skills to a higher level. Data from the study suggest that these students recognise the importance of skills in domains related to their academic progress (e.g., study skills, exam-taking techniques), learning to learn (e.g., persistence, curiosity, self-monitoring, researching, use of ICT Information Communication Technology), personal and social development (e.g., self-confidence, empathy, leadership, stress management), and career planning (e.g., setting career goals, obtaining information, selecting appropriate pathways). These domains are described more fully below, and small samples of verbatim comments (translated from Chinese to English for the purpose of this paper) are used to illustrate typical ideas and opinions expressed by the students during the discussions. 


\section{Academic development and learning to learn}

The following key areas of skills and attitudes were identified from analysis of the students' discussions:

- Academic development

Time management. Study skills. Examination skills. Learning with and from peers. Being a responsible and self-motivated learner.

- Learning to learn

Setting own goals. Self-monitoring. Acquiring skills and strategies for independent learning.

For high school adolescent students in Hong Kong, a major part of their school life is academic study. They have to face public examinations which can significantly influence their future, either for further study or for entry to the adult working world. At the time of this research study, Grade 11 (Form 5) students have to sit for the Hong Kong Certificate of Examination. Grade 13 (Form 7) students have to pass the Hong Kong Advanced Level Examination for the entry to university. It is important therefore that all students acquire skills for optimum academic development. During focus group discussions, time management, study techniques, exam-taking skills, and being a responsible and self-motivated learner were identified by the students as life skills essential for sound academic progress and ultimately for future employment. For example, these adolescents recognized how to arrange their limited time in school to create a sensible balance between study and other activities such as sport or being leaders in school teams. On this issue, one Grade 12 boy (S04) stated, "We do not have too much time to participate in activities like drama or singing contest. We need to concentrate on 
academic study." Similarly, a Grade 12 girl (S16) pointed out, "There are more things needing to be handled from Form Six, so how should we distribute our time? Hence time management is extremely important." A Grade 10 girl (S21) added, "Our teachers told us to create a timetable for this year. Although I think that I could never follow a timetable even if I create one, I have learnt how to do time management anyway." A Grade 10 boy (S22) remarked, "I would never study after school during Form One to Form Three, but I study hard now though, and spend less time on the computer games."

Most participants considered study skills and examination techniques to be vital for school success. For example, a Grade 10 girl (S21) pointed out, "I think that I have improved my listening ability after becoming a Form Four student, because I know that I cannot revise all the work at home without understanding it first. There is a lot of new stuff to learn each day, and I have to read every page thoroughly." A Grade 12 girl (S16) observed that a sound technique for taking exams was that you did not spend too much time on reading all the questions. She said, "I think that learning technique is very important in this situation." In terms of learning to learn (i.e., becoming more independent and self-motivated learners), the students appeared to recognise the importance of accepting responsibility for their own progress. A Grade 10 girl (S21) stated, "I keep my focus on what my teachers are saying in every lesson and I continuously tell myself to concentrate." Some participants emphasized the value of developing skills to help them acquire other important strategies involved in the 
learning process. These 'learning strategies' (mental plans of action) promote more self-directed learning and thus allow students to study more deeply and widely within and beyond the classroom setting. A Grade 12 boy (S64) commented, "Learning skills are important, and I have learnt a lot of those in this year. For instance, I have picked up some useful study skills from other students on how to get good grades."

\section{Personal and social development}

The following key areas of skills and attitudes were identified from analysis of the students' discussions:

- Personal and social development Understanding self. Understanding others. Cooperation and team spirit. Health and physical fitness. Avoiding drugs, drinking and smoking. Handling setbacks. Management of stress and emotion. Leisure-time management. Thinking and expressive skills. Self evaluation. Solving problems, and decision-making skills. Leadership skills.

Older adolescents are, of course, the senior students in their school, and they always have to take up responsibilities as leaders or core members in teams, clubs and societies. They are able to contribute to school life and ethos through working with peers and teachers. There are many situations that require social interaction with others in order to plan, make decisions, resolve conflicts, and where necessary to reach a compromise. Engaging in such situations is essential for the acquisition of relevant interpersonal life skills and for personal growth. It requires basically the understanding of self, understanding of others, cooperation, negotiation, team spirit and, where appropriate, leadership. In this study, students' awareness of the value of skills and abilities in the personal and social domains was evident. Through acquisition of these 
skills, adolescents are better at handling personal situations, maintaining self-improvement, building and maintaining good social relationships, and benefiting from social supports (Botvin, Griffin, \& Nichols, 2006; Sun \& Hui, 2007). For example, regarding getting along with schoolmates and making compromises, a Grade 10 girl (S14) said, "We have to learn to forgive. We may not need to go through the same experience to understand the feelings of others. We have to learn to observe others' emotions and reflect on how we should react afterwards. Sometimes we may say something that is hurting other people, but we do not realize." Another Grade 10 girl (S21) stated, "I have learnt to think before taking any action, to consider the feelings of other people, and understand them." In relation to cooperation and team spirit, one Grade 12 boy (S04) reported, "I have learnt how to cooperate and communicate with others in the drama competition. I have learnt how to work within a group to perform the drama." Another Grade 12 girl (S16) stated, "We must know how to work with other people in order to achieve our goal. We should maximize our strength to help and cooperate with each other." A Grade 12 boy (S12) contributed, "Joint-school functions involved a lot of meetings and discussions. These activities made me understand how to get along with people with different characters." One Grade 12 girl (S07) added, "Six Form is a totally new environment compared to the previous years. You meet many different people. You have to learn how to adjust yourself when communicating with them. You need to work with people with different personalities. These skills will all be useful in your future work." 
Some participants reported that they developed skills in self-regulation and self-

monitoring. For example, they reflected on their experiences and evaluated their academic performance and social relations. One Grade 10 boy (S28) stated, "In this year I found that I was at the bottom of the class all the time. I felt very depressed. I wanted to catch up with the rest of the class and did not just give up easily. In order to make up for the bad start I felt that I had to work harder than other students. I could not give up just because I was getting low marks. I have to work even harder, and not be bothered by the judgment of other people." The adolescents in this study also identified additional areas of life skill related to physical and mental health and fitness, for example, avoiding drugs, drinking and smoking, managing stress and emotions, handling life's setbacks, and using leisure-time management. Regarding at-risk health behavior and self-help, a Grade 12 boy (S02) recognised the positive influences of his peers: "I was a smoker before, but many of my friends managed to convince me that smoking was a bad behavior." Management of stress and emotions is essential for high school students. One Grade 12 girl (S01) stated, "Sometime I may feel extremely depressed and hopeless. I can try to view the situation from another point of view, try to analyze it objectively.” A Grade 12 girl (S13) reported, "I have to control my temper and manage my emotions carefully. I need to have high EQ [Emotional Quotient].” One Grade 10 girl (S25) added, "I can feel the enormous stress in high school. For me, handling pressure is a big issue. My way to solve this problem is that I would do the thing I enjoy most. I go swimming when I 
feel unhappy. I feel like I could release all the unhappiness when I was doing this.”

Skills in problem solving were also highlighted by the students as important in both academic and social areas. Some participants emphasized the importance of skills for thinking critically and making decisions. A Grade 12 girl (S01) stated, "I think skill in analyzing is very important as well; it helps a lot in solving everyday problems." A Grade 12 boy (S02) stated, "When you have to analyze an incident on your own, you will be able to do it naturally and spontaneously.” A Grade 10 girl (S27) added, “Teachers always said that we should think from different angles and not stick with a single point of view. For example we should not trust the news without independent thinking. Although newspapers always claim that they are fair, we should still use our own mind to judge if they are really fair. Newspapers may be wrong, just as the teachers may be wrong." Another Grade 10 girl (S23) reported, "In this year, my problemsolving and organizing abilities have improved."

The students also perceived the development of leadership skills to be important. For example, in relation to taking up responsible positions in school, a Grade 12 girl (S06) stated, "Due to fact that I have been the House Captain in this year, I have to learn many different skills when I work with other house members.” A Grade 12 boy (S12) said the benefit of leadership training course he attended was that, "I gained so much on how to hold a meeting and to guide the members to express their opinions. Back in school, I can make use of all that when I discuss with other students." 
Overall, the discussions indicated clearly that the students appreciated the importance of both intrapersonal and interpersonal skills in dealing with important situations in life. They were able to cite examples of skills they had acquired already, and they became more aware of skills they still needed to develop. They recognised that these skills were necessary not only in school but in working life.

\section{Career planning}

The following key areas of skill were identified from analysis of the students' discussions:

- Career planning

Setting career goals. Exploring possibilities. Career decision-making. Vocational training. Job hunting. Further study.

Making preparation for one's later career and for further study is an important stage for senior secondary students. All high school graduates have to face the challenge of finding desirable employment, often in a difficult job market. They need to understand that to be successful in this domain they must make prior preparations, including the development of relevant life skills.

Skills and strategies for career development for adolescents in Hong Kong must include identifying priorities in career planning, career goal-setting, obtaining relevant information, exploring possible career paths, vocational training selection, planning further studies, and job hunting. The comments from the participants in this study revealed a sound awareness of the importance of identifying their priorities and future needs in this area. For example, a Grade 12 girl (S03) remarked, "Sometimes you may mention that you are interested in a particular job, but in fact you do not really understand the nature of the job. I think that it would be wonderful 
if we can have opportunities for job internship." Another comment regarding preparation for job hunting also came from a Grade 12 girl (S07): "Some schools have job-interview simulation [role play], and this experience would be helpful.” Another Grade 10 girl (S18) recognised the value of learning on the job: "A lot of things can be learnt at work. If you have decided to look for a job, make sure that you can add value to yourself at work." A Grade 10 girl (S18) stated, "I feel that looking for a job is not a bad idea if someone really thinks that s/he is not going to be successful in studying. Forcing yourself to do more study may just be a waste of time." Regarding his future college plans, a Grade 12 boy (S12) said, "I have not picked the major that I am going to study in university yet. I feel like there are a lot of things I need to consider, and I am still not very sure about my interests at this moment."

The above data from the group discussions suggest clearly that students do indeed recognise that certain life skills are essential in several major developmental domains. The students also appear able to judge the extent to which they, as individuals, are developing or acquiring those skills.

\section{Influences affecting students' life skills development}

The second purpose of this study was to explore adolescents' perspectives on the factors that influenced their acquisition of life skills. Most of these factors were perceived to be within the school context, but outside influences were also identified. In the focus group discussions, participants talked first about activities within the school curriculum, extra-curricular activities, 
and aspects of the school's guidance and counseling program that could give them a sense of direction and provide opportunities to develop their talents. The students recognised that all teachers have a role to play in influencing students' development of life skills by, for example, deliberately teaching study skills within their subject area, encouraging cooperation and team work, fostering critical thinking and independence, and providing opportunities for talents to develop. To some extent, even the new Liberal Studies component recently introduced into the secondary curriculum in Hong Kong can provide all teachers with the opportunity to deal with issues relevant to life skills development, including critical thinking, data processing, reasoning, problem solving, and the effect of attitudes and values on individual's decisions and actions. In addition, in specific areas such as career planning and exploring future employment possibilities, teachers can give direct guidance and support, both at group and individual levels. At the present time, most schools in Hong Kong have developed a school-based guidance and counseling curriculum. In this curriculum, teachers develop tailor-made guidance and counseling activities to promote personal growth and to provide support. Some of the activities are designed for all students while others are directed at target groups or to individuals in need. Students in the focus groups perceived such programs and activities as contributing positively to their overall development of life skills. A Grade 12 boy (S12) reported, "The peercounselor scheme is most beneficial. It is the most direct way to keep in touch with senior students and learn skills from them. Students from junior forms can observe the way the seniors 
behave and their special qualities. Junior students can hence learn from the seniors." One Grade 12 girl (S44) highlighted the value of activities that deal with attitudes and behaviour toward others. She observed that "We have certain activities each month, for instance, this month is 'courtesy month' and next month is the 'gratitude month'.” Another Grade 10 girl (S14) commented on an individual planning activity that helped her begin to focus on career planning: "I remembered once in the assembly when teachers from each subject have to come to the stage and talk about their subjects. After the assembly, I was clear about my choices. This activity helped me a lot in doing subject selections, and I found out that there is a Careers Team in the school." Similarly, another Grade 12 girl (S17) highlighted how a particular action by the school helped her with career decisions. She commented: “Careers Team puts up posters regularly. These posters inform us about activities organized by universities or visits to universities. Through this channel I have a better understanding about the characteristics of different universities." At an individual level, guidance and counseling programs in school can help students with setting goals for a career path by, for example, assisting individuals to match their strengths (talents) to possible careers. At a more general level, all students can be exposed to a wider range of possible career paths, and can become acquainted with the specific skills and personal qualities that certain jobs require.

An additional aspect of a school's contribution to life skills development was identified by the students as 'extra opportunties for talent development'. While talent development should 
be an aim in all curriculum areas, schools frequently organize extra events that give adolescents an occasion to display their abilities to the full, to achieve, and realize their full potential. Such opportunities include extra-curricular activities and competitions, sometimes also affording the opportunity to take on leadership roles. Adolescents who take part in these activities gain real experiences that help them develop and apply life skills. One Grade 12 boy (S02) stated, "When you get to F.6 (Year 1 of Advanced Level Class) and become a House Committee member, you will feel that this is one of your responsibilities. You will learn this from each activity in the year." A Grade 10 girl (S27) stated, "I have been serving the school for quite a long time and I have been part of all the activities mentioned. For example, I am a member of the Chinese History Club and the Guidance Team. I am one of the core members of the class. I spend quite a lot of time joining school events, and I offer to help in such events."

Still within the school context, relationships with teachers and peers can have some influence on life skill development. In school, students are involved in daily interactions with various parties including teachers, other adults, and peers; and through these interactions adolescents need to apply, and thus develop, some of their life skills. For example, they may need to apply and strengthen basic skills such as problem solving, reasoning, communicating effectively, negotiating, and managing conflict. Regarding the role of peers, participants talked about instances in which they related well with peers through cooperation, team spirit, and leadership skills. One Grade 10 girl (S25) reported, "We, committee members, are responsible 
for organizing activities for club members. In theory each of us takes turn to do the work.

Whenever the workload is heavy, other committee members always offer their help proactively even though they are not responsible for that particular event. This shows the strong bonding between us and we really work as a group."

In terms of influences on their life skills development, the students also mentioned additional factors outside the school context, such as relationships within the family and relationships with peers. Even though adolescents spend increasing amounts of time with their peers, family relationships still exert a significant influence on how adolescents develop life skills. When adolescents receive frequent support, encouragement, two-way communication, and authoritative parenting from open-minded parents, they tend to have better opportunity for life skills development. In addition to relationships with parents, sibling relations also play a role in life skills development in so far as good sibling relations can help promote aspects of personal and social development (e.g., communication, empathy, understanding of others, responsibility, cooperation, and leadership). For example, a Grade 10 boy (S02) stated, "I feel that the influence from the family is enormous, though you may not notice the life skills that the family has brought to you". Another Grade 12 boy (S12) stated, "I have mentioned that I take schoolwork seriously. My mother has modeled this attitude to me again and again when I was small. For example, whenever my mother found out my writing was not good, she would point it out and ask me to rewrite it immediately. Eventually I have developed the habit to do my 
work responsibly and set high standards for myself". A Grade 12 girl (S60) reported, "When you share your views and feelings with family members, you are using your communication skills. These skills were cultivated in us since we were small." Life skills also include those involved in compromise and negotiation, as a Grade 12 girl (S16) pointed out: "I used to argue and fight with my little brother in the past. However I am not strong enough to fight with him any more and so I shift my focus to making settlement rather than fight.” A family's hopes and aspirations for their child also influence a student's motivation and desire to achieve, and thus acquire the necessary skills for life. For example, a Grade 12 girl (S61) stated, "Family has great influence on us. We, as children, always hope to make our parents proud of us. It's natural that my parents have high expectations on me."

Overall, the focus group students' comments revealed an awareness of important contextual factors that affect life skills development in adolescents. These included the learning of skills and attitudes within the context of the mainstream curriculum, via school guidance and counseling activities, and through extra opportunities to develop their talents. Beyond the context of school, students perceived that family relationships and peer relationships to exert an influence on their acquisition of life skills.

\section{Enhancing students' life skills development}

Automatic development of life skills cannot be assumed by teachers; and this fact was readily acknowledged by the students. They suggested a variety of additional focused activities 
that they wished their schools would introduce, including internships and training camps to enhance career and personal and social life skills development. For example, one Grade 12 girl (S03) commented, "I suggest that school can cooperate with some business sectors and refer some students do internships in the business environment during long holidays such as summer holiday." A Grade 10 girl (S51) stated, "We have been to the H K Exchange for a visit and learnt a lot from people who worked there. Schools should organize more of these kinds of activities, and invite professionals to give speeches in school so that we can know more about application of knowledge in life." A Grade 10 boy (S52) stated, "More day camps and camping activities can be organized so that students can learn life skills in a practical way. For example, students can learn about teamwork when doing a group task in the camp." Another Grade 10 girl (S24) stated, "When we attend the camp, our relationship no longer works in a teacherstudent manner but in a more balanced way, like friends. In a leisure camp, we can learn more about real life skills beyond the knowledge we learn in classes at school." Another Grade 12 girl (S13) suggested, "School could organize training camps which invite speakers to teach a variety of skills, including communication. Besides, when we live together in a camp, the student-teacher relationship will be strengthened." It was clear that these students greatly value the inclusion of real-life experiences in their school activities, and also having their teachers share their own experiences and opinions on everyday life matters. A Grade 12 girl (S44) emphasized, "I think teachers have to spend more time in communicating with students and 
sharing their experiences."

Guidance activities that strengthen self-esteem, encourage caring attitudes and foster teamwork were also suggested as effective means to enhance life skills development. According to the students, having a positive attitude is important in taking the first steps in applying life skills.

\section{Discussion and implications}

The present study explored, for the first time, Hong Kong Chinese adolescents' perceptions of their own life skills development and the importance they place on such skills. Life skills help students cope with the many demands and stresses that can occur during the period of puberty and adolescence, and can prepare students for the transition to adult life (Lehr, Hanson, Sinclair, \& Christenson, 2003; Neumark-Sztainer, Paxton, Hannan, Haines, \& Story, 2006). The study also investigated the within-school and outside-school influences that may help develop and enhance life skills development. The findings indicated students' awareness of many salient life skills, including those related directly to academic development, 'learning to learn', personalsocial growth, and future career planning. The students were also able to suggest practical strategies that schools might use to further enhance students' life skills development. Contextual factors influencing the development of life skills appear to include not only experiences within the school curriculum and the guidance and counselling programme, but also talent development opportunities, and family and peer relationships. 
In respect to the key domains of life skills, the findings of this study support the conclusions reached by Nyutu and Gysbers (2006). They identified five areas of counseling needs among high school adolescents, namely human relationships, career development, selfdevelopment, social values and learning skills. These career, academic and personal and social development life skills are consistent with the content of the comprehensive school guidance program operating in the U.S.A. (Gybsers, 2008). With regard to practical strategies, the students suggested many authentic daily school life experiences and out-of-school activities. The students seem to be aware of the importance of balancing their time and energy in leisure activities and academic study. This accords with the recent education reform in Hong Kong, in particular, all high school students are requested to engage in community service, aesthetic and physical activities, and career-related experiences in the classroom and beyond (Education Bureau, 2009). The findings also suggest a need for secondary schools to place even greater emphasis on teaching senior students the skills and strategies required for career planning and preparation. Adopting a whole-school approach, career education should be implemented where possible within the mainstream curriculum, supplemented also through specific activities within other guidance curriculum activities.

In relation to the perceived influences of teachers, peers and family on adolescents' life skills development, this study provides support for the adoption of a whole school policy on providing a nurturing supportive environment for all students, including the gifted and other 
students with special needs. The policy supports teachers in their guidance role of collaborating with guidance professionals to conduct guidance curriculum, student individual planning and talent development activities. Pre-service and in-service professional development programmes for teachers are essential to prepare them for guidance work and the effective implementation of a whole school approach (Lau \& Fung, 2008). Such professional training should also highlight for teachers the importance of fostering students' life skills development.

\section{Limitations}

The students were a selected sample comprising those who were already actively involved in extra-curricular activities and leadership roles in their schools. Their perceptions might differ from those of students who are less involved and less successful. These selected students were also senior students in Grades 10 to 12 (age 15 to 18). It cannot be assumed that younger students would necessarily have the same views, particularly those related to skills for career planning. Future studies could compare the perceptions of students across an even wider range of Hong Kong high schools, and investigate age level differences in students' understanding and appreciation of life skills. In addition, it would be of interest to international researchers to develop a quantitative survey to compare adolescents' perceptions of life skills across different countries and regions (Yuen, 2008).

\section{References}


Bandura, A. (1990) Multidimensional scales of perceived self-efficacy. Stanford, CA: Stanford University.

Becker, B. E., \& Luthar, S. S. (2007) Peer-perceived admiration and social preference:

Contextual correlates of positive peer regard among suburban and urban adolescents, Journal of Research on Adolescence, 17(1), 117-114.

Botvin, G. J., Griffin, K. W., \& Nichols, T. D. (2006) Preventing youth violence and delinquency through a universal school-based prevention approach, Prevention Science, 7(4), 403-408.

Carey, M.A. (1995). Concerns in the analysis of focus group data. Qualitative Health Research, $5(4), 487-495$

Education Bureau (HKSAR.)(2009) Other learning experiences. Available online at: http://cd1.edb.hkedcity.net/cd/lwl/ole/01_intro_01.asp ( accessed 6 January 2010)

Education Commission (HKSAR) (2002) Learning for life, learning through life: Reform proposals for the education system in Hong Kong. Hong Kong Special Administrative Region of the People's Republic of China: Education Commission.

Gottlieb, G., Wahslsten, D. \& Lickliter, R. (2006). The significance of biology for human development: A developmental psychobiological systems view. In W. Damon \& R. Lerner (Eds.), Handbook of child psychology (6 ${ }^{\text {th }}$ ed.). New York: Wiley.

Gould, M.S., Greenberg, T. , Velting, D.M., \& Shaffer, D. (2003). Youth suicide risk and preventive interventions: A review of the past 10 years. Journal of the American Academy 
of Child and Adolescent Psyhciatry, 42, 386-405.

Gysbers, N. C. (2008) Individual student planning in the United States: Rationale, practices, and results, Asian Journal of Counselling, 15(2), 117-140

Gysbers, N. C. (2003) Improving the life skills curriculum and the comprehensive guidance program: concepts and strategies. In M. Yuen, P.S.Y. Lau, T.K.M. Leung, P. M.K. Shea, R.M.C. Chan, E.K.P. Hui, \& N.C. Gysbers (2003). Life skills development and comprehensive guidance program: Theories and practices (pp. 22-35). Hong Kong, China: Life Skills Development Project, Faculty of Education, the University of Hong Kong.

Gysbers, N.C. \& Hendersen, P. (2000) Developing and managing your school guidance program. Alexandria, VA: American Counseling Association.

Gysbers, N.C., Lapan, R., Multon, K., \& Lukin, L. (1996) Missouri guidance competency evaluation surveys: Examiner's manual and guide to interpretation and use. Jefferson City, MO: Missouri Department of Elementary and Secondary Education.

Halcomb, E.J., Gholizadeth, L., Digiacomo, M., Phillips, J., \& Davidson, P.M. (2007). Literature review: considerations in undertaking focus group research with culturally and linguistically diverse groups. Journal of Clinical Nursing 16, 1000-1011.

Ho, Y.-F. (2008). Reflections on school career education in Hong Kong: Responses to Norman C. Gysbers, Darryl Takizo Yagi, and Sang Min lee \& Eunjoo Yang. Asian Journal of Counseling, 15(2), 183-206. 
Lang, P. L.F. (2003) Affective education in schools: A personal response. In M. Yuen, P.S.Y.

Lau, T.K.M. Leung, P. M.K. Shea, R.M.C. Chan, E.K.P. Hui, \& N.C. Gysbers (2003).

Life skills development and comprehensive guidance program: Theories and practices (pp.

36-45). Hong Kong, China: Life Skills Development Project, Faculty of Education, the -

University of Hong Kong.

Lau, P. S.Y. \& Fung, S.-C. (2008) School guidance and counseling in an international context: a reaction paper. Asian Journal of Counselling, 15(2), 207-228.

Lehr, C.A., Hanson, A., Sinclair, M.F. \& Christenson, S.L. (2003). Moving beyond dropout prevention towards school completion. School Psychology Review, 32, 342-364.

McMahon, M. \& Yuen, M. (2009). Career counseling and internationalization. Asian Journal of Counselling, 16(2), 91-111.

Michels, T. M., Kropp, R. Y., Eyre, S. L., Halpern-Felsher, B. L. (2005) Initiating sexual experiences: How do young adolescents make decisions regarding early sexual activity? Journal of Research on Adolescence, 15(4), 583-607.

Miles, M.B., \& Huberman, A.M. (1994) Qualitative data analysis. London: Sage.

Morgan, D. (1988) Focus groups as qualitative research. Newbury Park: Sage.

Neumark-Sztainer, D., Paxton, S.J., Hannan, P.J., Haines, J. \& Story, M. (2006). Does body satisfaction matter? Five-year longitudinal associations between body satisfaction and 
health behaviors in adolescent females and males. Journal of Adolescent Health, 39, 244251.

Nyutu, P.N., \& Gysbers, N.C. (2008) Assessing the counselling needs of counseling students in Kenya, International Journal of Educational and Vocational Guidance, 8, 83-94.

Ormrod, J. (2008). Educational psychology (6 ${ }^{\text {th }}$ ed). Upper Saddle River, NJ: Merrill.

Phipps, B. J. (1995) Career dreams of preadolescent students, Journal of Career Development, 22(1), 19-32.

Puchta, C. \& Potter, J. (2004). Focus group practice. London: SAGE.

Santrock, J.W. (2008). Life-span development (10 ${ }^{\text {th }}$ ed.). New York: McGraw Hill.

Sun, R. C. F., \& Hui, E. K. P. (2007) Building social support for adolescents with suicidal ideation: Implications for school guidance and counseling, British Journal of Guidance \& Counseling, 35(3), 299-309.

Unicef (United Nations Children's Fund). (2009) Which skills are life skills? Available online at: http://www.unicef.org/lifeskills/index_whichskills.html (accessed 08 January 2010).

Weiten W. (2001). Psychology: Themes and variations, (5 ${ }^{\text {th }}$ ed.). Belmont, CA: WadsworthThomson.

Wright, M.S., Wilson, D.K., Griffin, S., \& Evans, A. (2010). A qualitative study of parental modeling and social support for physical activity in underserved adolescents. Health 
Education Research, 25(2), 224-232.

Yuen, M. (2008). School counseling: Current international perspectives, Asian Journal of Counselling, 15(2), 103-116.

Yuen, M., Chan, R.M.C., Lau, P. S.Y., Gysbers, N.C., \& Shea, P.M.K. (2007) Comprehensive guidance and counseling programmes in the primary schools of Hong Kong: Teachers' perceptions and involvement, Pastoral Care in Education, 25(4), 17-24.

Yuen, M., Lau, P. S.Y., Shek, D. T.L., \& Lam, M.P. (2002) Confirmatory factor analysis and reliability of the Chinese version of the Maslach Burnout Inventory among guidance teachers in Hong Kong, Psychological Reports, 91, 1081-1086.

Yuen, M., Shea, P. M.K., Leung, T.K.M., Hui, E. K.P., Lau, P. S.Y., \& Chan, R.M.C. (2003) Enhancing students' life skills development. In M. Yuen, P.S.Y. Lau, T.K.M. Leung, P. M.K. Shea, R.M.C. Chan, E.K.P. Hui, \& N.C. Gysbers (2003). Life skills development and comprehensive guidance program: Theories and practices (pp. 5-21). Hong Kong, China: Life Skills Development Project, Faculty of Education, the University of Hong Kong. 


\section{Appendix 1 FOCUS GROUP DISCUSSION TOPICS}

- What are the 'life skills' that you use in school, at home, and in the community? Please provide us with some examples. Tell us your own stories of applying life skills in any areas.

- How have you acquired or developed these skills at home, in school, and in the community? Please provide us with some examples.

- What guidance activities at school do you find most useful for life skills development? What activities do you think are less useful?

- What do teachers do that you find useful for developing your own life skills? What would you suggest that teachers should do more of, to help you develop life skills?

- What activities do you suggest the school should introduce that would help you to develop life skills?

- Any additional comments or suggestions? 